\title{
Environmental and resources footprints between China and EU countries
}

\author{
Xu Tian ${ }^{\mathrm{a}, \mathrm{c}}$, Rui Wu $\mathrm{u}^{\mathrm{a}, \mathrm{d}}$, Yong Geng ${ }^{\mathrm{a}, \mathrm{b}^{*}}$, Raimund Bleischwitz ${ }^{\mathrm{e}}$, Yihui Chen ${ }^{\mathrm{f}}$
}

a School of Environmental Science and Engineering, Shanghai Jiao Tong University, Shanghai 200240, China

b China Institute for Urban Governance, Shanghai Jiao Tong University, No. 800 Dongchuan Road, Minhang, Shanghai, 200240, China

c School of Mechanical Engineering, Shanghai Jiao Tong University, Shanghai 200240, China

d Business School, Nanjing Normal University, No. 1 Wenyuan Road, Nanjing, 210023, China

e Institute for Sustainable Resources, University College London, Central House, 14 Upper Woburn Place, London WC1H 0NN, United Kingdom

f Yunnan Provincial Research Academy of Environmental Science, Kunming 650034, China

*Corresponding author: ygeng@sjtu.edu.cn (Y. Geng) Telephone: +86-21-54748019, Fax: $+86-21-54740825$.

\begin{abstract}
International trade has accelerated the trend of globalization, giving consumers and countries the opportunity to reach new markets and products. However, it also brought negative externalities in the forms of pollution and environmental degradation. Plus, the large amounts of resource flows among different countries may aggravate resource depletion. Thus, it is necessary to uncover the embodied resource flows and corresponding environmental impacts so that sustainable trade policies can be raised. Under such a circumstance, this paper accounts environmental and resources footprints embodied in the China-EU trade for the year of 2008 by employing a multi-regional input-output model, including both the global and sectoral environmental and resource footprints which caused by the trade between China and the EU-27 countries. Research results show that from the global footprints perspective, the total environmental footprints of China and EU countries are $4.73 \mathrm{Gt}$ and $4.53 \mathrm{Gt}$ in 2008, respectively. The total resource footprints of China are $8.19 \mathrm{E}+07 \mathrm{TJ}$ of energy, 0.66 Bha of land, 14.5 Gt of materials, and 1.47 Tm3 of water, while such figures for EU countries are 1.17E+08 TJ of energy, $0.66 \mathrm{Bha}$ of land, $12.1 \mathrm{Gt}$ of materials, and $1.26 \mathrm{Tm}^{3}$ of water, respectively. The transfer trend of environmental and resources footprints between China and EU was also analyzed, indicating that EU countries caused 8.21 times of emission footprint than China's, and China provided 6.25 times of energy footprint, 16.76 times of land footprint, 12.26 times of material footprint, and 17.38 times of water footprint for EU countries' final consumption. In addition, the sectoral footprints between China and the five selected EU countries were analyzed. Finally, policy implications from environmental and resources management perspectives are proposed
\end{abstract}

Key words: footprint; consumption; China; EU 


\section{Introduction}

In the era of globalization, processes of consumption and production are increasingly disconnected. International supply chains transcend political and geographical borders, following a rationale of competitive advantages in numerous regions. Consumption therefore appears as a distant and indirect driver of various environmental impacts across the whole world, often occurring in developing or emerging countries where major processes of extraction and production take place (Giljum, 2004; Kovanda et al., 2010;Kovanda and Weinzettel, 2013). This reality contrasts with traditional territorial accounting methods, as those cannot comprise international drivers and inherently give a bias for sustainable consumption in those territories that have outsourced environmentally-intensive production processes to other countries (Hoekstra and Wiedmann, 2014; Moran et al., 2013; Wiedmann et al., 2015). The Sustainable Development Goals (SDG) 12 of sustainable consumption and production to be achieved by the year 2030 therefore implies more comprehensive approaches with an appropriate inclusion of international trade (Peters et al., 2011a; Wiedmann, 2009).

In order to understand environmental changes and resultant impacts from consumption process, and also complement the monetary evaluation perspective of international trade, Footprint methods have been developed to capture such ambitions since 1990s (Geng et al., 2014). Footprints have been measured by using indictors which reflect human pressure on the environment. Several kinds of footprint indicators such as ecological footprint, water footprint, land footprint, carbon footprint, biodiversity footprint and also material footprint from consumption perspective have been studied during the past decades (Hoekstra and Wiedmann, 2014). A number of policy initiatives have also begun to consider such broader perspectives, e.g. the OECD green growth initiative, the G7, the European Commission, the United Nations Green Economy Initiative, the United Nations Ten Year Framework of Programs on Sustainable Consumption and Production, and Circular Economy, Resource-efficiency, and Reduce, Re-use and Recycle (3R) initiatives (Tukker et al., 2016; Geng et al., 2016).

Academically, many relevant studies were published, focusing on the assessments of land footprints, water footprints, material footprints, and also carbon footprints. For instance, Dong and her colleagues first evaluated regional water footprint at the provincial level (Dong et al., 2012) and then extended their study for the whole China (Dong et al., 2014), uncovering that current trade pattern among different Chinese regions resulted in further water scarcity in the water shortage areas and it is crucial to adjust the trade structure. Based on the EXIOBASE database and from both production and consumption perspectives, Tukker et al., (2016) evaluated carbon footprints, water footprints, land footprints, and material footprints in EU for the year of 2007 and clarified the general patterns of these four footprints in different EU countries. As such, by using the same database, Giljum et al., (2016) assessed the material footprints in EU countries for the period of 1995-2011 and identified the main products flows among different countries and their corresponding impacts from final consumption perspective. Many similar studies were also conducted, implying that domestic and international supply chains have dynamic 
impacts on both resources flows and environmental quality (Bruckner et al., 2012; Ewing et al., 2012; Hoekstra and Wiedmann, 2014; Peters et al., 2011a; Steenolsen et al., 2012). From methodological point of view, three methods proved to be capable of assessing footprints, including an input-output analysis method (top-down approach), a coefficient method based on process analyses (bottom-up approach) and a hybrid method combining both top-down and bottom-up approaches (Dong et al., 2013; Giljum et al., 2013).

From practical point of view, EU has become the largest trade partner of China since 2004, while China has become the second largest trade partner of EU since 2005. The total trade volume between China and EU reached 574.3 billion USD in 2015, among which 187.1 billion USD is the export from EU to China (9.4\% of EU's total export) and 387.2 billion use is the export from China to EU (17.1\% of China's total export) (Wang et al., 2016). Due to such large volumes in both sides, it is critical to understand the related transfer patterns of environmental and resources flows between China and EU and identify the key contribution sectors of related footprints so that appropriate policies can be raised to promote sustainable trade.

Unfortunately, very few studies have been published to investigate the complex footprints transfer between China and EU. Therefore, it is critical to initiate such a study so that the related footprints patterns can be uncovered. In order to achieve such a research objective, a multiregional input-output (MRIO) approach is applied in this study. Such an approach can identify the complex supply chains as the whole economic system is included in the calculation system (Giljum et al., 2014; Lenzen et al., 2013; Wiedmann et al., 2011). Also, identify the key contribution footprints sectors of each country will be identified and the related results will be compared based on the different database so that appropriate policy insights can be raised to mitigate the unbalanced resource flows and reduce the overall environmental emissions (Hoekstra and Wiedmann, 2014; Moran et al., 2013; Wiedmann et al., 2015).

The whole paper is structured as follows. After this introduction section, Section 2 presents research methods, including a description of footprints calculation, as well as data sources used in this study. Section 3 presents the research results. Section 4 discusses related policy implications. Section 5 concludes the whole paper.

\section{Methods and data sources}

\subsection{Methods}

A fully integrated multi-regional input-output (MRIO) method was applied in order to calculate trade-related environmental and resources footprints between China and the EU countries. The input-output analysis method was first proposed and developed by Professor Wassily Leontief in the late 1930s (Leontief, 1936, 1941), in which observed economic data for a particular economic area (nation, province, city, etc.) are used for building up a basic input-output model. Evans (1955) and Moses (1955) further developed the MRIO method in 1950s, which is an extension of a single-region model by recognizing the interconnections between regions in an 
operational way. By focusing on environmental perspectives, an environmental MRIO model accounts for the global economic and environmental impact of one country's consumption (Miller and Blair, 2009; Peters et al., 2011b).

In order to expand one MRIO model from one country to the global level, the bilateral trade $e^{r s}$ (exports from region $r$ to $s$ ) needs to be decomposed into exports for intermediate use $\left(A^{r s} x^{s}\right)$ and for final consumption $\left(y^{r s}\right)$. The standard MRIO model sums up intermediate and final consumption in order to get the total output in each region and can be expressed in equation (1).

$\mathrm{x}^{\mathrm{r}}=\mathrm{Z}^{\mathrm{rr}}+\mathrm{y}^{\mathrm{rr}}+\sum_{\mathrm{s} \neq \mathrm{r}} \mathrm{e}^{\mathrm{rs}}=\mathrm{A}^{\mathrm{rr}} \mathrm{x}^{\mathrm{r}}+\mathrm{y}^{\mathrm{rr}}+\sum_{\mathrm{s} \neq \mathrm{r}} \mathrm{A}^{\mathrm{rs}} \mathrm{X}^{\mathrm{s}}+\sum_{\mathrm{s} \neq \mathrm{r}} \mathrm{y}^{\mathrm{rs}}$

Where $\mathrm{x}^{\mathrm{r}}$ is the total output in region $\mathrm{r}$; domestic intermediate consumption in region $r$ is represented by matrix $Z^{r r}$ and domestic final consumption (households, governments and gross fixed capital formation) is represented by vector $y^{r r}$, both excluding imports; $A^{r r}$ is a matrix made up of domestic direct requirement coefficients between different sectors in region $r$, while $A^{r s}$ represents exported direct requirement coefficients matrix from region $r$ to $s$. By considering the equation in each region the matrix form can be further expressed in equation (2).

$$
\left(\begin{array}{c}
x^{1} \\
x^{2} \\
x^{3} \\
\vdots \\
x^{m}
\end{array}\right)=\left(\begin{array}{ccccc}
A^{11} & A^{12} & A^{13} & \cdots & A^{1 m} \\
A^{21} & A^{22} & A^{23} & \cdots & A^{2 m} \\
A^{31} & A^{32} & A^{33} & \cdots & A^{3 m} \\
\vdots & \vdots & \vdots & \ddots & \vdots \\
A^{m 1} & A^{m 2} & A^{m 3} & \cdots & A^{m m}
\end{array}\right)\left(\begin{array}{c}
x^{1} \\
x^{2} \\
x^{3} \\
\vdots \\
x^{m}
\end{array}\right)+\left(\begin{array}{c}
\sum_{r} y^{1 r} \\
\sum_{r} y^{2 r} \\
\sum_{r} y^{3 r} \\
\vdots \\
\sum_{r} y^{m r}
\end{array}\right)
$$

Where each block matrix $A$ represents the interactions between industries and countries. The diagonal matrix blocks show the domestic activities, while the off-diagonal matrix blocks show the trade patterns between different regions. The footprint of country $r\left(\mathrm{~F}^{\mathrm{r}}\right)$ can be calculated by using equation (3).

$$
\left(\begin{array}{c}
\mathrm{F}^{\mathrm{Ir}} \\
\mathrm{F}^{2 \mathrm{r}} \\
\mathrm{F}^{3 \mathrm{r}} \\
\vdots \\
\mathrm{F}^{\mathrm{mr}}
\end{array}\right)=\left(\begin{array}{ccccc}
\hat{\mathrm{S}}^{1} & 0 & 0 & \cdots & 0 \\
0 & \hat{\mathrm{S}}^{2} & 0 & \cdots & 0 \\
0 & 0 & \hat{\mathrm{S}}^{3} & \cdots & 0 \\
\vdots & \vdots & \vdots & \ddots & \vdots \\
0 & 0 & 0 & \cdots & \hat{\mathrm{S}}^{\mathrm{m}}
\end{array}\right)\left\{\left(\begin{array}{ccccc}
\mathrm{I} & 0 & 0 & \cdots & 0 \\
0 & \mathrm{I} & 0 & \cdots & 0 \\
0 & 0 & \mathrm{I} & \cdots & 0 \\
\vdots & \vdots & \vdots & \ddots & \vdots \\
0 & 0 & 0 & \cdots & \mathrm{I}
\end{array}\right)-\left(\begin{array}{ccccc}
\mathrm{A}^{11} & \mathrm{~A}^{12} & \mathrm{~A}^{13} & \cdots & \mathrm{A}^{\mathrm{Im}} \\
\mathrm{A}^{21} & \mathrm{~A}^{22} & \mathrm{~A}^{23} & \cdots & \mathrm{A}^{2 \mathrm{~m}} \\
\mathrm{~A}^{31} & \mathrm{~A}^{32} & \mathrm{~A}^{33} & \cdots & \mathrm{A}^{3 \mathrm{~m}} \\
\vdots & \vdots & \vdots & \ddots & \vdots \\
\mathrm{A}^{\mathrm{m} 1} & \mathrm{~A}^{\mathrm{m} 2} & \mathrm{~A}^{\mathrm{m} 3} & \cdots & \mathrm{A}^{\mathrm{mm}}
\end{array}\right)\right\}^{-1}\left(\begin{array}{c}
\mathrm{y}^{1 \mathrm{r}} \\
\mathrm{y}^{2 \mathrm{r}} \\
\mathrm{y}^{3 \mathrm{r}} \\
\vdots \\
\mathrm{y}^{\mathrm{mr}}
\end{array}\right)
$$

Where, $F^{m r}$ is a vector representing the footprint of consumption taking place in $r$ from resource extraction place $m$. The sum of all elements in vectors $F^{1 r}$ to $F^{m r}$ represents country $r$ 's footprint. $\widehat{S}^{\mathrm{m}}$ is a diagonal matrix containing domestic resource and environmental coefficients for each industry in region $m$. Equation (3) provides a better understanding of national footprints, which is matrix multiplication of domestic resource and environmental coefficients matrix, Leontief inverse matrix and domestic final consumption matrix. National footprints link upstream supply chain resource extraction and emissions with final goods and services consumption.

\subsection{Data sources}

The world input-output tables and resources and emissions amounts for the year of 
2008 were obtained from the World Input-Output Database (WIOD). WIOD is a project funded by the European Union's Seventh Framework Program for research and technological development, covering 35 sectors and 41 countries or regions (Timmer et al., 2015). In general terms, the variables cover: use of energy; emission of main greenhouse gases; emission of other main air pollutants; use of mineral and fossil resources; land use; and water use. This study mainly covers two kinds of footprints: environmental and resources footprints. Environmental footprints mainly focus on 7 different types of emissions: $\mathrm{CH}_{4}, \mathrm{~N}_{2} \mathrm{O}, \mathrm{NO}_{\mathrm{X}}, \mathrm{SO}_{\mathrm{X}}, \mathrm{CO}, \mathrm{NMVOC}$, and $\mathrm{NH}_{3}$, which cover global warming, acidification, and tropospheric ozone formation potential perspectives. Resources footprints mainly focus on 4 different types of resources: energy (coal, oil, gas, waste, renewables and electricity), land (arable, pastures and forest), materials (biomass, fossil and minerals), and water (blue, green and grey). The natural resource extraction refers to the annual amounts of solid, liquid and gaseous raw materials extracted or moved from the natural environment by humans or human-controlled technologies (Genty et al., 2012). In this study, it comprises extracted resources which enter the economic system for further processing or direct consumption excluding unused extracted resources that never enter the economic system. All resource extraction coefficients are domestic extractions excluding import.

\section{Results}

\subsection{The total environmental and resource footprints of China and EU countries}

The total environmental footprints of China and EU countries for the year of 2008 are $4.73 \mathrm{Gt}$ and $4.53 \mathrm{Gt}$, respectively. Among all the EU countries, the top ten total environmental footprints countries are Germany, United Kingdom, Italy, France, Spain, Poland, Netherlands, Greece, Belgium, and Romania, accounting for 19.57\%, $13.63 \%, 11.62 \%, 10.64 \%, 8.40 \%, 6.35 \%, 4.26 \%, 3.26 \%, 2.90 \%$, and $2.35 \%$ of EU's total environmental footprints, respectively.

The total resource footprints of China for the year of 2008 are $8.19 \mathrm{E}+07 \mathrm{TJ}$ of energy, 0.66 Bha of land, 14.5 Gt of materials, and $1.47 \mathrm{Tm}^{3}$ of water, respectively. The components of different items are shown in Figure 1. It is clear that the largest consumption footprints on energy, land, materials, and water in each category are coal $(54 \%)$, pastures land $(61 \%)$, minerals $(65 \%)$ and green water $(56 \%)$. 


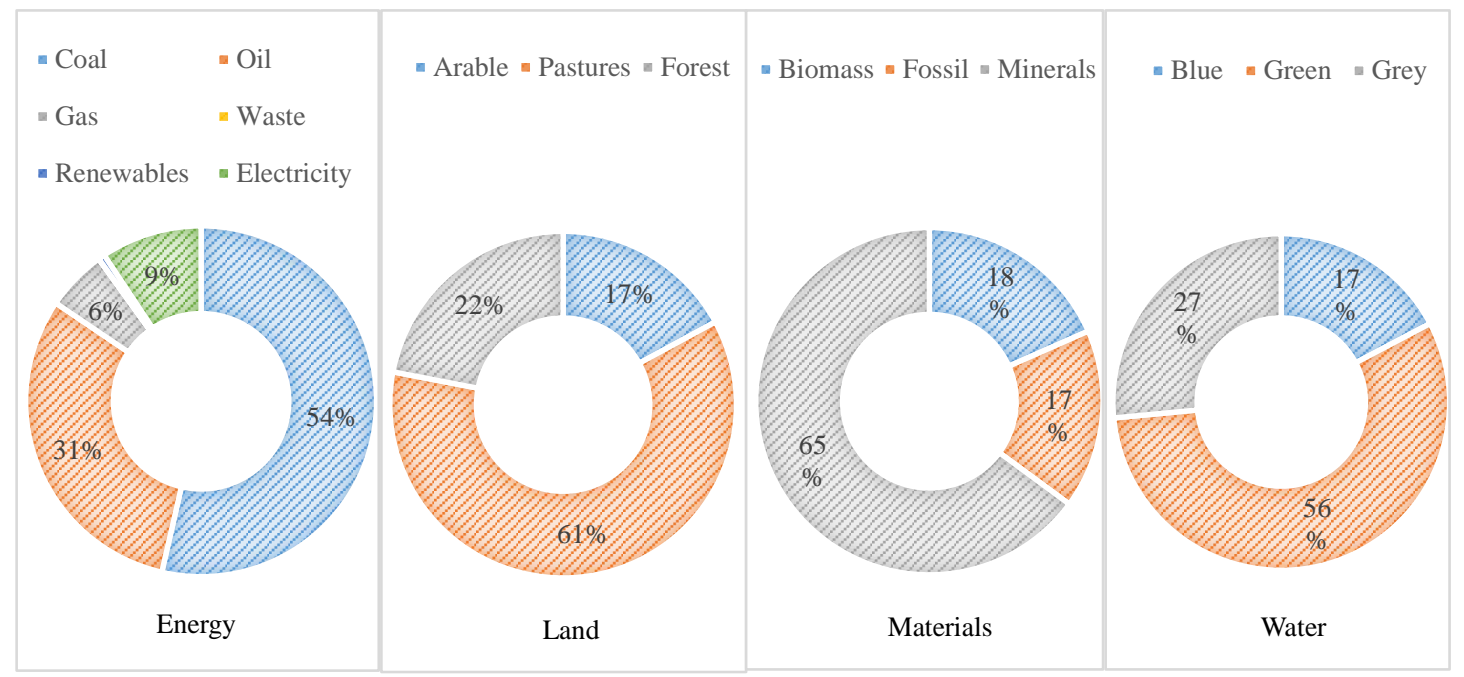

Figure 1 China's consumption of energy, land, materials, and water in 2008

The total resources footprints of EU countries for the year of 2008 are 1.17E+08 TJ of energy, 0.66 Bha of land, $12.1 \mathrm{Gt}$ of materials, and $1.26 \mathrm{Tm}^{3}$ of water, respectively. Figure 2 shows the detailed components of different items. It is clear that the largest consumption footprints of energy, land, materials, and water are oil (54\%), pastures land (42\%), minerals (51\%) and green water (68\%). Among the EU countries, the top ten energy consumption countries are Germany, United Kingdom, France, Italy, Spain, Poland, Netherlands, Belgium, Greece, and Sweden, accounting for $18.59 \%, 12.70 \%, 12.46 \%, 12.11 \%, 9.09 \%, 4.76 \%, 4.25 \%, 3.21 \%, 2.94 \%$, and $2.37 \%$ of the EU's total energy footprint, respectively. The top ten land consumption countries are Germany, United Kingdom, France, Spain, Italy, Netherlands, Poland, Finland, Sweden, and Belgium, accounting for $16.23 \%, 12.71 \%, 12.30 \%, 10.50 \%$, $9.85 \%, 4.82 \%, 4.52 \%, 3.57 \%, 3.38 \%$, and $3.16 \%$ of the EU's total land footprint, respectively. The top ten materials consumption countries are Germany, France, Italy, United Kingdom, Spain, Poland, Romania, Greece, Netherlands, and Belgium, accounting for $19.52 \%, 12.01 \%, 10.86 \%, 10.47 \%, 9.45 \%, 5.10 \%, 3.80 \%, 3.80 \%$, $3.46 \%$, and $2.43 \%$ of the EU's total materials footprint, respectively. The top ten water consumption countries are Germany, France, Italy, United Kingdom, Spain, Poland, Romania, Netherlands, Sweden, and Belgium, accounting for $15.77 \%$, $12.80 \%, 11.45 \%, 10.98 \%, 10.77 \%, 5.35 \%, 4.38 \%, 4.00 \%, 2.83 \%$, and $2.76 \%$ of the EU's total water footprint, respectively. 


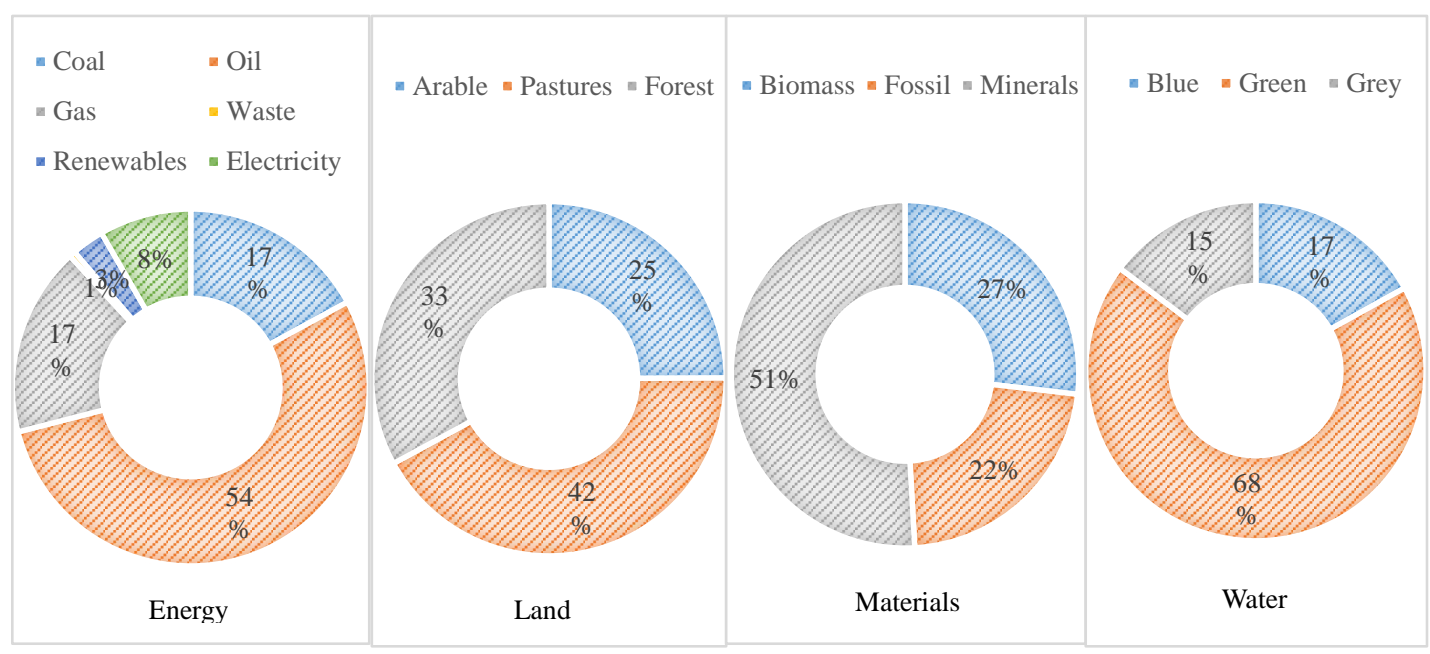

Figure 2 EU's consumption of energy, land, materials, and water in 2008

\subsection{The environmental and resource footprints between China and the EU countries}

The total emission footprint, energy footprint, land footprint, material footprint, and water footprint of the EU countries caused by China's final consumption for the year of 2008 are $2.24 \mathrm{E}+07$ tons, $5.33 \mathrm{E}+05 \mathrm{TJ}, 1.22 \mathrm{E}+03 \mathrm{kha}, 4.80 \mathrm{E}+04 \mathrm{ktons}$, and $2.87 \mathrm{E}+06 \mathrm{~km}^{3}$, respectively. As such, China's total emission footprint, energy footprint, land footprint, material footprint, and water footprint caused by the EU countries' final consumption for the year of 2008 are $2.06 \mathrm{E}+08$ tons, $3.86 \mathrm{E}+06 \mathrm{TJ}$, $2.16 \mathrm{E}+04 \mathrm{kha}, 6.36 \mathrm{E}+05 \mathrm{ktons}$, and $5.27 \mathrm{E}+07 \mathrm{~km}^{3}$, respectively. Such comparison results illustrate that the EU countries caused 8.21 times of emission footprint than China's, and China contributed 6.25 times of energy footprint, 16.76 times of land footprint, 12.26 times of material footprint, and 17.38 times of water footprint for the EU countries' final consumption.

Among all the EU countries, the top six environmental and resource footprints countries caused by China's final consumption are Germany, Italy, France, United Kingdom, Netherlands, and Denmark, while the top six environmental and resource footprints countries which China contributed to their final consumption are Germany, Italy, France, United Kingdom, Spain and Netherlands. Figure 3 provides more details, in which it is clear that China contributed more environmental and resources footprint to the selected EU countries' final consumption. 

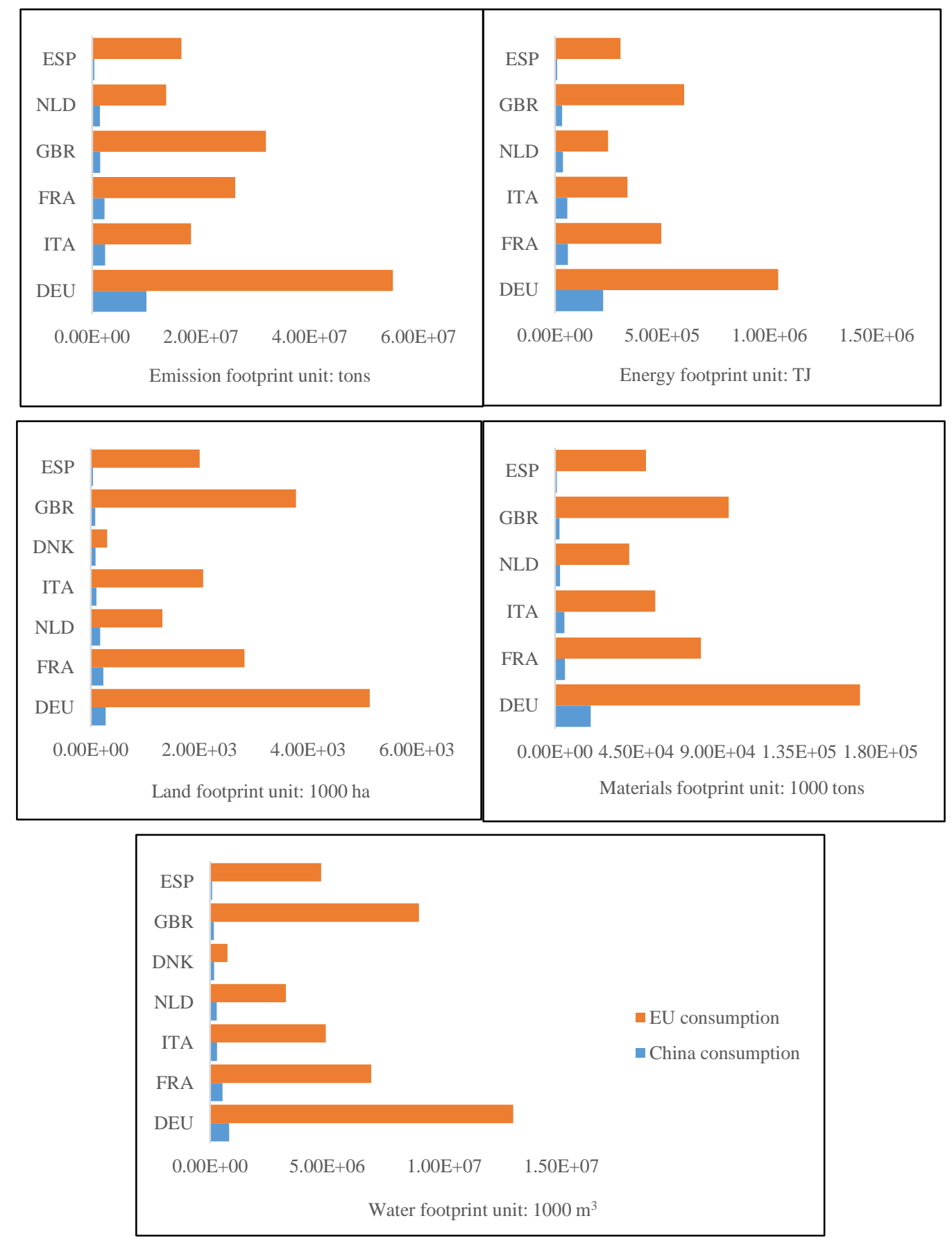

Figure 3 Top countries' footprint of China and EU consumption

\subsection{Transferred environmental and resource footprints between China and the selected EU countries}

In order to have more detailed explanations on transferred environmental and resource footprints between China and the selected EU countries, some famous EU countries, including Germany, Italy, France, United Kingdom, and Netherlands, were selected for further studies.

Germany. The total environmental footprint of Germany is $8.85 \mathrm{E}+08$ tons, and the total resource footprints are $2.17 \mathrm{E}+07 \mathrm{TJ}$ of energy, $1.07 \mathrm{E}+05 \mathrm{kha}$ of land, $2.37 \mathrm{E}+06 \mathrm{ktons}$ of materials, and $1.98 \mathrm{E}+08 \mathrm{~km}^{3}$ of water for the year 2008 , 
respectively.

From the production perspective, the domestic extraction of above mentioned items in Germany are 8.93E+08 tons of emissions, 2.05E+07 TJ of energy, 2.49E+04 kha of land, $1.08 \mathrm{E}+06 \mathrm{ktons}$ of materials, and $6.76 \mathrm{E}+07 \mathrm{~km}^{3}$ of water. These results indicate that except for emissions, Germany needs to obtain other resources through trade in order to satisfy the needs of its final consumption. In this regard, China provided $20.20 \%$ of emission footprint, $13.71 \%$ of energy footprint, $8.99 \%$ of land footprint, $19.76 \%$ of materials footprint, and $12.95 \%$ of water footprint. Likewise, in order to meet the final consumption of China, Germany provided $10.74 \%$ of emission footprint, $9.85 \%$ of energy footprint, $1.49 \%$ of land footprint, $9.70 \%$ of materials footprint, and $3.04 \%$ of water footprint.

From sectoral perspective, the top five environmental and resources sectors with transferred environmental and resource footprints between China and Germany are shown in Figure 4. Table 1 lists all the abbreviations for Figure 4. For China, due to Germany's final consumption, the top one sector of emission footprint, energy footprint, land footprint, materials footprint and water footprint is the Electrical and Optical Equipment sector, Electrical and Optical Equipment sector, Textiles and Textile Products sector, Electrical and Optical Equipment sector, and Textiles and Textile Products sector, accounting for $41.23 \%, 41.63 \%, 36.91 \%, 38.51 \%$, and $31.71 \%$ of the corresponding totals with each item, respectively. For Germany, due to China's final consumption, the top one sector of emission footprint, energy footprint, land footprint, materials footprint and water footprint is Machinery sector, Machinery sector, Machinery sector, Machinery sector, and Machinery sector, accounting for $44.34 \%, 42.65 \%, 38.54 \%, 44.29 \%$, and $41.51 \%$ of the corresponding totals, respectively.

Italy. The total environmental footprint of Italy is $5.26 \mathrm{E}+08$ tons, and the total resource footprints are 1.42E+07 TJ of energy, 6.46E+04 kha of land, 1.32E+06 ktons of materials, and $1.44 \mathrm{E}+08 \mathrm{~km}^{3}$ of water for the year 2008 , respectively. From the production perspective, the domestic extraction of the above mentioned items in Italy are $4.82 \mathrm{E}+08$ tons of emissions, $1.24 \mathrm{E}+07 \mathrm{TJ}$ of energy, $1.77 \mathrm{E}+04$ kha of land, $5.60 \mathrm{E}+05 \mathrm{ktons}$ of materials, and $8.06 \mathrm{E}+07 \mathrm{~km}^{3}$ of water. These results indicate that Italy needs to obtain other resources through trade in order to satisfy the needs of its final consumption. In this regard, China provided $17.13 \%$ of emission footprint, $10.85 \%$ of energy footprint, $7.75 \%$ of land footprint, $19.55 \%$ of materials footprint, and $10.98 \%$ of water footprint. Likewise, in order to meet the final consumption of China, Italy provided $2.54 \%$ of emission footprint, $2.48 \%$ of energy footprint, $0.58 \%$ of land footprint, $2.51 \%$ of materials footprint, and $1.12 \%$ of water footprint.

From sectoral perspective, the top five environmental and resources sectors with transferred environmental and resource footprints between China and Italy are shown in Figure 4. For China, due to Italy's final consumption, the top one sector of emission footprint, energy footprint, land footprint, materials footprint and water footprint is Electrical and Optical Equipment sector, Electrical and Optical Equipment sector, Textiles and Textile Products sector, Electrical and Optical Equipment sector, Textiles 
and Textile Products sector, accounting for $29.35 \%, 29.97 \%, 44.53 \%, 27.43 \%$, and $40.34 \%$ of the corresponding totals, respectively. For Italy, due to China's final consumption, the top one sector of emission footprint, energy footprint, land footprint, materials footprint and water footprint is Machinery sector, Machinery sector, Machinery sector, Machinery sector, and Machinery sector, accounting for $53.30 \%$, $51.70 \%, 34.02 \%, 52.45 \%$, and $39.74 \%$ of the corresponding totals, respectively.

France. The total environmental footprints of France is $4.82 \mathrm{E}+08$ tons, and the total resource footprints are $1.46 \mathrm{E}+07 \mathrm{TJ}$ of energy, $8.08 \mathrm{E}+04 \mathrm{kha}$ of land, $1.46 \mathrm{E}+06 \mathrm{ktons}$ of materials, and $1.61 \mathrm{E}+08 \mathrm{~km}^{3}$ of water for the year 2008 , respectively. From the production perspective, the domestic extraction of above mentioned items in France are $4.07 \mathrm{E}+08$ tons of emissions, $1.20 \mathrm{E}+07 \mathrm{TJ}$ of energy, 4.29E+04 kha of land, $7.19 \mathrm{E}+05 \mathrm{ktons}$ of materials, and $1.10 \mathrm{E}+08 \mathrm{~km}^{3}$ of water. These results indicate that France needs to obtain other resources through trade in order to satisfy the needs of its final consumption. In this regard, China provided $17.95 \%$ of emission footprint, $10.81 \%$ of energy footprint, $7.76 \%$ of land footprint, $20.29 \%$ of materials footprint, and $11.35 \%$ of water footprint. Likewise, in order to meet the final consumption of China, France provided $2.46 \%$ of emission footprint, $2.60 \%$ of energy footprint, $1.25 \%$ of land footprint, $2.69 \%$ of materials footprint, and $1.95 \%$ of water footprint.

From sectoral perspective, the top five environmental and resources sectors with transferred environmental and resource footprints between China and France are shown in Figure 4. For China, due to France's final consumption, the top one sector of emission footprint, energy footprint, land footprint, materials footprint and water footprint is Electrical and Optical Equipment sector, Electrical and Optical Equipment sector, Textiles and Textile Products sector, Electrical and Optical Equipment sector, Textiles and Textile Products sector, accounting for $34.97 \%, 35.21 \%, 46.51 \%, 32.44 \%$, and $41.39 \%$ of the corresponding totals, respectively. For France, due to China's final consumption, the top one sector of emission footprint, energy footprint, land footprint, materials footprint and water footprint is Transport Equipment sector, Transport Equipment sector, Food, Beverages and Tobacco sector, Transport Equipment sector, Food, Beverages and Tobacco sector, accounting for 34.68\%, 31.77\%, 58.42\%, $29.94 \%$, and $47.70 \%$ of the corresponding totals, respectively.

United Kingdom. The total environmental footprints of United Kingdom is 6.17E+08 tons, and the total resources footprints are $1.48 \mathrm{E}+07 \mathrm{TJ}$ of energy, $8.35 \mathrm{E}+04 \mathrm{kha}$ of land, $1.27 \mathrm{E}+06 \mathrm{ktons}$ of materials, and $1.38 \mathrm{E}+08 \mathrm{~km}^{3}$ of water for the year 2008 , respectively. From the production perspective, the domestic extraction of the above mentioned items in United Kingdom are 6.02E+08 tons of emissions, 1.33E+07 TJ of energy, 2.02E+04 kha of land, 5.91E+05 ktons of materials, and $3.11 \mathrm{E}+07 \mathrm{~km}^{3}$ of water. These results indicate that United Kingdom needs to obtain other resources through trade in order to satisfy the needs of its final consumption. In this regard, China provided $18.67 \%$ of emission footprint, $11.11 \%$ of energy footprint, $8.29 \%$ of land footprint, $20.55 \%$ of materials footprint, and $12.17 \%$ of water footprint. Likewise, in order to meet the final consumption of China, United Kingdom provided $1.58 \%$ of 
emission footprint, $1.42 \%$ of energy footprint, $0.45 \%$ of land footprint, $1.18 \%$ of materials footprint, and $0.61 \%$ of water footprint.

From sectoral perspective, the top five environmental and resources sectors with the transferred environmental and resource footprints between China and United Kingdom are shown in Figure 4. For China, due to United Kingdom's final consumption, the top one sector of emission footprint, energy footprint, land footprint, materials footprint and water footprint are Electrical and Optical Equipment sector, Electrical and Optical Equipment sector, Textiles and Textile Products sector, Electrical and Optical Equipment sector, Textiles and Textile Products sector, accounting for $25.90 \%, 26.12 \%, 47.24 \%, 24.54 \%$, and $43.33 \%$ of the corresponding totals, respectively. For United Kingdom, due to China's final consumption, the top one sector of emission footprint, energy footprint, land footprint, materials footprint and water footprint are Machinery sector, Machinery sector, Food, Beverages and Tobacco sector, Machinery sector, Food, Beverages and Tobacco sector, accounting for $24.23 \%, 23.51 \%, 26.40 \%, 25.84 \%$, and $18.78 \%$ of the corresponding totals, respectively.

Netherland. The total environmental footprints of Netherland is $1.93 \mathrm{E}+08$ tons, and the total resources footprints are 4.97E+06 TJ of energy, 3.17E+04 kha of land, $4.20 \mathrm{E}+05 \mathrm{ktons}$ of materials, and $5.03 \mathrm{E}+07 \mathrm{~km}^{3}$ of water for the year 2008 , respectively. From the production perspective, the domestic extraction of the above mentioned items in Netherland are 2.10E+08 tons of emissions, $7.23 \mathrm{E}+06 \mathrm{TJ}$ of energy, $2.17 \mathrm{E}+03 \mathrm{kha}$ of land, $1.38 \mathrm{E}+05 \mathrm{ktons}$ of materials, and $5.89 \mathrm{E}+06 \mathrm{~km}^{3}$ of water. These results indicate that except for emission and energy items, Netherland needs to obtain other resources through trade in order to satisfy the needs of its final consumption. For China and Netherland, in order to meet the final consumption of Netherland, China provided $21.12 \%$ of emission footprint, $12.58 \%$ of energy footprint, $6.56 \%$ of land footprint, $21.11 \%$ of materials footprint, and $10.33 \%$ of water footprint. Likewise, in order to meet the final consumption of China, Netherland provided $1.52 \%$ of emission footprint, $1.59 \%$ of energy footprint, $0.95 \%$ of land footprint, $1.39 \%$ of materials footprint, and $1.03 \%$ of water footprint.

From sectoral perspective, the top five environmental and resources sectors with transferred environmental and resource footprints between China and Netherland are shown in Figure 4. For China, due to Netherland's final consumption, the top one sector of emission footprint, energy footprint, land footprint, materials footprint and water footprint are Electrical and Optical Equipment sector, Electrical and Optical Equipment sector, Textiles and Textile Products sector, Electrical and Optical Equipment sector, Textiles and Textile Products sector, accounting for $22.06 \%$, $22.94 \%, 22.67 \%, 20.81 \%$, and $20.00 \%$ of the corresponding totals, respectively. For Netherland, due to China's final consumption, the top one sector of emission footprint, energy footprint, land footprint, materials footprint and water footprint are Machinery sector, Machinery sector, Food, Beverages and Tobacco sector, Machinery sector, Food, Beverages and Tobacco sector, accounting for 20.78\%, 20.39\%, 66.93\%, $21.09 \%$, and $58.58 \%$ of the corresponding totals, respectively. 

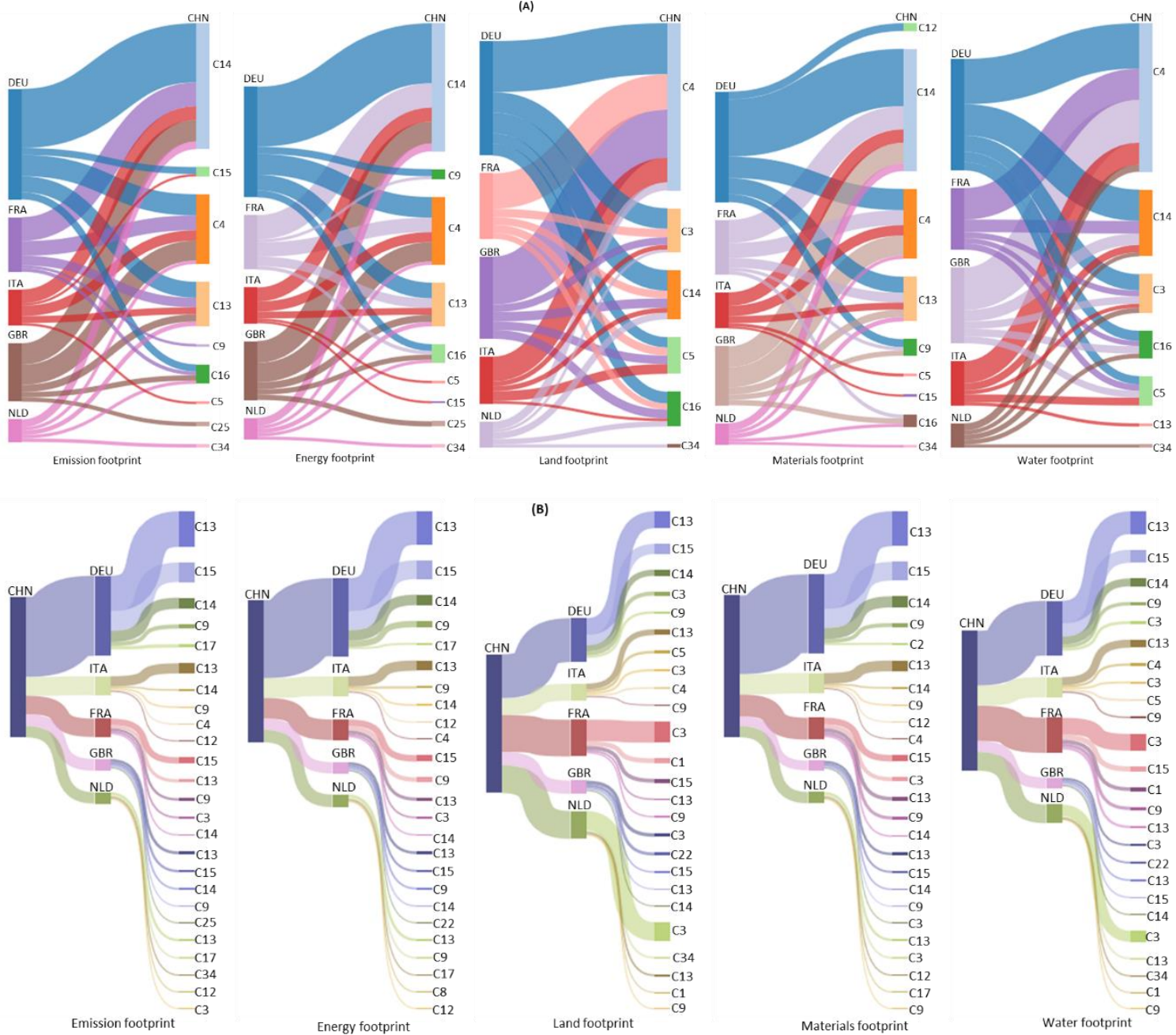

Figure 4 Sectorial footprints between China and the selected EU countries. Note: Here CHN represents China; DEU represents Germany; FRA represents France; GBR represents United Kingdom; ITA represents Italy; NLD represents Netherland.

Table 1 Abbreviation for different sectors listed in Fig. 4.

\begin{tabular}{ll}
\hline Abbreviation & Sector \\
\hline C1 & Agriculture, Hunting, Forestry and Fishing \\
C2 & Mining and Quarrying \\
C3 & Food, Beverages and Tobacco \\
C4 & Textiles and Textile Products \\
C5 & Leather, Leather and Footwear \\
C8 & Coke, Refined Petroleum and Nuclear Fuel \\
C9 & Chemicals and Chemical Products \\
C12 & Basic Metals and Fabricated Metal \\
C13 & Machinery, Nec \\
C14 & Electrical and Optical Equipment \\
C15 & Transport Equipment \\
C16 & Manufacturing, Nec; Recycling \\
C17 & Electricity, Gas and Water Supply \\
\hline
\end{tabular}




\begin{tabular}{ll}
\hline C22 & Hotels and Restaurants \\
C25 & Air Transport \\
C34 & Other Community, Social and Personal Services \\
\hline
\end{tabular}

\section{Discussions and policy implications}

With regard to the global environmental and resources footprints caused by China and EU countries' final consumption, except for energy footprint, the other footprints caused by China's final consumption are higher than those caused by EU countries' final consumption. From per capital perspective, China's per capital environmental footprint, energy footprint, land footprint, materials footprint and water footprint are 3.57 tons, $0.06 \mathrm{TJ}, 0.50 \mathrm{ha}, 10.91$ tons, and $1.11 \mathrm{~km}^{3}$, respectively, while the EU's per capital footprints are 9.10 tons, $0.24 \mathrm{TJ}, 1.32$ ha, 24.38 tons, and $2.53 \mathrm{~km}^{3}$, respectively. In addition, the transferred footprints between China and EU countries show that China provided more footprints for EU countries' final consumption, while EU countries provided less footprints for China's final consumption. Such findings indicate that the developed EU countries have higher resource consumption and obtained more embodied resources, but transferred more environmental impacts to China by means of international trade (Dorninger and Hornborg, 2015; Giljum et al., 2014; Steenolsen et al., 2012).

The sectoral study results also indicate that those sectors with more complicated production processes consume more resources and produced more emissions than the primary sectors. Particularly, those sectors with higher footprints have also the larger trade volumes. The industry structures are diversity in different countries, that why the high footprint sectors are different in selected countries. Therefore, in order to decrease the resources consumption and environmental impact, country should mainly focus on their own important sectors, and find out the suitable way to improve it rather than use the same style with the other countries. Besides that, each country should consider that how to promote the resource efficiency and reduce the environmental emissions.

The global trade significantly improved the economic development of all the involved countries, which can bring positive impacts to trade partners. However, such activities also induced a large amount of resource and environmental emissions transfer. Due to more advanced technologies and equipment, those developed countries can easily obtain trade advantages over those developing countries by selling their high valued products. However, those developing countries have to sell their natural resources or low value-added products in order to get more sophisticated products, leading to more environmental concerns and resource depletion issues. Such an international trade trend cannot be sustainable if no further actions are taken. Therefore, it is critical for all the trade partners to work together so that integrated efforts can be made.

First of all, in order to improve the resource efficiency, sustainable resource management should be adopted by all the countries. In this regard, the first step is to establish an international resource database so that embodied energy, emissions and resource footprints can be accounted to all the trade countries. Such a database should 
be dynamically updated so that the trade trend can be monitored. Moreover, some innovative efforts, such as circular economy, industrial ecology, cleaner production, and eco-design, should be promoted so that the overall resource efficiency can be improved (Bleischwitz, 2010; Geng et al., 2013; Tian et al., 2016). In addition, energy structure optimization should be encouraged. Although different countries may have different energy endowments, renewable energy (such as solar power, geothermal power, wind power hydro-power, etc) should be fully promoted by considering the local situations.

Second, economic instruments should be adopted in order to control the overall use of natural resources and reduce the overall emissions. For instance, resource and emission tax should be imposed in developing countries so that these countries can get more money to deal with their resource depletion and environmental emissions. However, the tax rates should be carefully set up so that tax will not impede international trade. Also, appropriate pricing policies should be released. Many developing countries sell their resource and primary products at much lower prices so that they can have more international customers. In some cases, due to malign competition they set up much lower prices (even lower than their final costs), leading to the fact that they cannot recover their costs and ignore the contribution of natural ecosystems. When they prepare their prices, they often ignore the environmental externalities. Such an unsustainable pricing strategy will eventually result in the collapse of local natural ecosystem and suffer the local residents' public benefits. Consequently, it is crucial for the developing countries to internalize the environmental externalities for pricing their exported products.

Third, technology transfer should be supported. Most developing countries do not have advanced technologies and equipment for extracting and processing natural resources, as well as for end-of-pipe treatment. They have to rely on basic and backward tools and technologies for mining natural resources, resulting in increasingly severe environmental pollution and resource depletion. Unfortunately, the decreasing natural resource and the deteriorating ecosystems will eventually influence the developed world. Therefore, developed countries should seek appropriate channels to transfer their advanced technologies and equipment to their trade partners in the developing world. During such a process, necessary training activities should be initiated so that workers in the developing countries can grasp necessary skills. Also, financial help may be simultaneously provided since most developing countries do not have adequate funds.

Fourth, capacity-building activities should be applied worldwide. With rapid technological development and increasing incomes, people prefer to purchase more sophisticated and energy intensive products, leading to increasing energy and material demands. Under such a circumstance, it is critical to promote sustainable consumption so that people can change their behaviors toward low carbon or green consumption. Useful capacity building efforts include workshops, TV/radio/internet promotions, pamphlets, and regular school education. These activities may enhance people's environmental awareness and guide all the stakeholders' actions. However, these activities may cost significantly. Thus, governmental agencies and corporate world 
should work together so that necessary funds can be collected. Moreover, international organizations, such as United Nations Environmental Program (UNEP), and the World Bank, should actively support these activities. Especially, efforts should focus on those developing countries, where people's environmental awareness is weak and financial capacity is limited.

\section{Conclusions}

Trade globalization facilitated economic integration among different countries by exchanging capitals, goods, and services across the international borders. Significant benefits can be obtained to all the trade partners, such as technological improvement, information sharing, economic prosperity, poverty reduction, etc. However, due to imbalanced economic development, countries with more advanced development always benefit more than their counterparts in the developing world. It is necessary to identify the embodied energy and material flows among different countries so that sustainable resource use can be applied at the global level. Under such a circumstance, this study focuses on examining environmental and resource footprints between China and EU countries by applying a MRIO model.

The results show that China's environmental footprint, energy footprint, land footprint, materials footprint and water footprint are $4.73 \mathrm{Gt}, 8.19 \mathrm{E}+07 \mathrm{TJ}, 0.66 \mathrm{Bha}$, 14.5 Gt and $1.47 \mathrm{Tm}^{3}$, while these items of EU are $4.53 \mathrm{Gt}, 1.17 \mathrm{E}+08 \mathrm{TJ}, 0.66 \mathrm{Bha}$, 12.1 Gt and $1.26 \mathrm{Tm}^{3}$ for the year 2008, respectively. From per capital footprint perspective, China's per capital environmental footprint, energy footprint, land footprint, materials footprint and water footprint of China are 3.57 tons, $0.06 \mathrm{TJ}, 0.50$ ha, 10.91 tons, and $1.11 \mathrm{~km}^{3}$ for the year 2008, respectively, while such figures for EU are 9.10 tons, $0.24 \mathrm{TJ}, 1.32 \mathrm{ha}, 24.38$ tons, and $2.53 \mathrm{~km}^{3}$ for the year 2008, respectively. Although China's overall footprints are higher than the EU countries, its per capital footprints are smaller than those in EU. From final consumption point of view, China provided 6.25 times of energy footprint, 16.76 times of land footprint, 12.26 times of material footprint, and 17.38 times of water footprint for EU countries' final consumption. From sectoral point of view, China's Electrical and Optical Equipment sector and Textiles and Textile Products sector are the main sectors to provide environmental and resource footprints for five EU countries' final consumption. Likewise, in order to meet China's final consumption, Machinery sector is the main sector for Germany and Italy to provide footprints to China; Transport Equipment sector, Food, Beverages and Tobacco sector are the main sectors for France to provide footprints to China; Machinery sector and Food, Beverages and Tobacco sector are the main sectors for United Kingdom and Netherlands to provide footprint for China.

In general, trade globalization induces complicated resource flows and the transfer of environmental emissions among different countries. This study provides useful policy implications for trade policy makers so that they could learn how different kinds of footprints exchange between trade partners at the global level, and identify which sectors contribute more footprints to trade partner's final consumption. 
These findings may help different countries to quantify environmental and resources losses related with international trade, identify the key sectors and make appropriate resource policies. Several policy suggestions have also been raised, including rational resource use, appropriate application of economic instruments, technology transfer and capacity building efforts.

\section{Acknowledgment}

This study is supported by the Natural Science Foundation of China (71690241, 71461137008, 71325006, and 71704104), the Fundamental Research Funds for the Central Universities through Shanghai Jiao Tong University (16JCCS04), the Shanghai Municipal Government (17XD1401800), and Yunnan Provincial Research Academy of Environmental Science. 


\section{References}

Bleischwitz, R. (2010) International economics of resource productivity - Relevance, measurement, empirical trends, innovation, resource policies. International Economics \& Economic Policy 7, 227-244.

Bruckner, M., Giljum, S., Lutz, C., Wiebe, K.S. (2012) Materials embodied in international trade-Global material extraction and consumption between 1995 and 2005. Global Environmental Change 22, 568-576.

Dong, H., Geng, Y., Fujita, T., Fujii, M., Hao, D., Yu, X. (2014) Uncovering regional disparity of China's water footprint and inter-provincial virtual water flows. Science of the Total Environment 500-501, 120.

Dong, H., Geng, Y., Sarkis, J., Fujita, T., Okadera, T., Xue, B. (2012) Regional water footprint evaluation in China: A case of Liaoning. Science of the Total Environment 442, 215-224.

Dong, H., Geng, Y., Xi, F., Fujita, T. (2013) Carbon footprint evaluation at industrial park level: a hybrid life cycle assessment approach. Energy policy 57, 298-307.

Dorninger, C., Hornborg, A. (2015) Can EEMRIO analyses establish the occurrence of ecologically unequal exchange? Ecological Economics 119, 414-418.

Evans, W.D., Chenery, H.B., Clark, P.G., Cao-Pinna, V. (1955) The Structure and Growth of the Italian Economy. Econometrica 23(1),110.

Ewing, B.R., Hawkins, T.R., Wiedmann, T.O., Galli, A., Ercin, A.E., Weinzettel, J., Steen-Olsen, K. (2012) Integrating ecological and water footprint accounting in a multi-regional input-output framework. Ecological Indicators 23, 1-8.

Geng, Y., Sarkis, J., Ulgiati, S., Zhang, P. (2013) Measuring China's circular economy. Science 339, 1526-1527.

Geng, Y., Zhang, L.M., Chen, X.D., Xue, B., Fujita, T., Dong, H.J. (2014). Urban ecological footprint analysis: a comparative study between Shenyang in China and Kawasaki in Japan. J. Clean. Prod. 75, 130-142.

Geng, Y., Sarkis, J., Ulgiati, S. (2016) Sustainability, well-being, and the circular economy in China and worldwide. Science. 6278 (Supplement): 73-76, Special issue on Pushing the boundaries of scientific research: 120 years of addressing global issues.

Genty, A., Arto, I., Neuwahl, F., (2012) Final database of environmental satellite accounts: technical report on their compilation, WIOD Deliverable 4.6, Documentation. http://www.wiod.org/publications/source_docs/Environmental_Sources.pdf

Giljum, S. (2004) Trade, Materials Flows, and Economic Development in the South: The Example of Chile. Journal of industrial ecology 8, 241-261.

Giljum, S., Bruckner, M., Martinez, A. (2014) Material Footprint Assessment in a Global Input-Output Framework. Journal of industrial ecology 19, 792-804.

Giljum, S., Lutter, S., Bruckner, M., Aparcana, S. (2013) A review and evaluation of available methods and data to calculate footprint-type (consumption-based) indicators for materials, water, land and carbon. Sustainable Europe Research Institute (SERI), Austria.

Giljum, S., Wieland, H., Lutter, S. (2016) Identifying priority areas for European resource policies: a MRIO-based material footprint assessment. Journal of Economic Structures 5, 1-24.

Hoekstra, A.Y., Wiedmann, T.O. (2014) Humanity's unsustainable environmental footprint. science 344, 1114-1117.

Kovanda, J., Weinzettel, J. (2013) The importance of raw material equivalents in economy-wide 
material flow accounting and its policy dimension. Environmental Science \& Policy 29, 71-80.

Kovanda, J., Weinzettel, J., Hák, T. (2010) Material Flow Indicators in the Czech Republic in Light of the Accession to the European Union. Journal of industrial ecology 14, 650-665.

Lenzen, M., Moran, D., Kanemoto, K., Geschke, A. (2013) Building eora: a global Multi-region Input-output database at high country and sector resolution. Economic Systems Research 25, 20-49.

Leontief, W.W. (1936) Quantitative input and output relations in the economic systems of the United States. The review of economic statistics, 105-125.

Leontief, W.W. (1941) Structure of American economy, 1919-1929.

Miller, R.E., Blair, P.D. (2009) Input-output analysis: foundations and extensions. Cambridge University Press, UK.

Moran, D.D., Lenzen, M., Kanemoto, K., Geschke, A. (2013) Does ecologically unequal exchange occur? Ecological Economics 89, 177-186.

Moses, L.N. (1955) The stability of interregional trading patterns and input-output analysis. The American Economic Review, 803-826.

Peters, G.P., Minx, J.C., Weber, C.L., Edenhofer, O. (2011a) Growth in emission transfers via international trade from 1990 to 2008. Proceedings of the National Academy of Sciences of the United States of America 108, 8903-8908.

Peters, G.P., Minx, J.C., Weber, C.L., Edenhofer, O. (2011b) Growth in emission transfers via international trade from 1990 to 2008. Proceedings of the National Academy of Sciences of the United States of America 108, 8903-8908.

Steenolsen, K., Weinzettel, J., Cranston, G., Ercin, A.E., Hertwich, E.G. (2012) Carbon, land, and water footprint accounts for the European Union: consumption, production, and displacements through international trade. Environmental science \& technology 46, 10883-10891.

Tian, X., Geng, Y., Dai, H., Fujita, T., Wu, R., Liu, Z., Masui, T., Yang, X. (2016) The effects of household consumption pattern on regional development: A case study of Shanghai. Energy 103, 49-60. Timmer, M.P., Dietzenbacher, E., Los, B., Stehrer, R., de Vries, G.J. (2015) An Illustrated User Guide to the World Input-Output Database: the Case of Global Automotive Production. Review of International Economics 23, 575-605.

Tukker, A., Bulavskaya, T., Giljum, S., Koning, A.D., Lutter, S., Simas, M., Stadler, K., Wood, R. (2016) Environmental and resource footprints in a global context: Europe's structural deficit in resource endowments is. Global Environmental Change 40, 171-181.

Wang, X., Liang, R., Peng, Y., 2016. An overview of China's international trade for its $12^{\text {th }}$ five-year plan and perspectives on its 13th five-year plan. International Trade 3, 4-13.

Wiedmann, T. (2009) A review of recent multi-region input-output models used for consumption-based emission and resource accounting. Ecological Economics 69, 211-222.

Wiedmann, T., Wilting, H.C., Lenzen, M., Lutter, S., Palm, V. (2011) Quo vadis MRIO? Methodological, data and institutional requirements for multi-region input-output analysis. Ecological Economics 70, 1937-1945.

Wiedmann, T.O., Schandl, H., Lenzen, M., Moran, D., Suh, S., West, J., Kanemoto, K. (2015) The material footprint of nations. Proceedings of the National Academy of Sciences of the United States of America 112, 6271-6276. 